\title{
Missed opportunities for family planning counselling among HIV-positive women receiving HIV Care in Uganda
}

\author{
Juliet Nabirye ${ }^{1 \dagger}$, Joseph K. B. Matovu ${ }^{1,2^{*} \dagger}$, John Baptist Bwanika ${ }^{1}$, Fredrick Makumbi ${ }^{1}$ and Rhoda K. Wanyenze
}

\begin{abstract}
Introduction: HIV-positive women who are still in the reproductive years need adequate sexual and reproductive health information to make informed reproductive health choices. However, many HIV-positive women who interface with the health system continue to miss out on this information. We sought to: a) determine the proportion of HIV-positive women enrolled in HIV care who missed family planning (FP) counselling; and b) assess if any association existed between receipt of FP counselling and current use of modern contraception to inform programming.

Methods: Data were drawn from a quantitative national cross-sectional survey of 5198 HIV-positive women receiving HIV care at 245 HIV clinics in Uganda; conducted between August and November 2016. Family planning counselling was defined as provision of FP information (i.e. available FP methods and choices) to an HIV-positive woman by a health provider during ANC, at the time of delivery or at the PNC visit. Analyses on receipt of FP counselling were done on 2760 HIV-positive women aged 15-49 years who were not currently pregnant and did not intend to have children in the future. We used a modified Poisson regression model to determine the Prevalence Ratio (PR) as a measure of association between receipt of any FP counselling and current use of modern contraception, controlling for potential confounders. Analyses were performed using STATA statistical software, version 14.1.

Results: Overall, 2104 (76.2\%) HIV-positive women reported that they received FP counselling at any of the three critical time-points. Of the $24 \%(n=656)$ who did not, 37.9\% missed FP counselling at ANC; $41 \%$ missed FP counselling during delivery; while $54 \%$ missed FP counselling at the post-natal care visit. HIV-positive women who received any FP counselling were significantly more likely to report current use of modern contraception than those who did not (adjusted PR [adj. PR] = 1.21; 95\% Confidence Interval [Cl]: 1.10, 1.33).
\end{abstract}

Conclusion: Nearly one-quarter of HIV-positive women did not receive any form of FP counselling when they interfaced with the healthcare system. This presents a missed opportunity for prevention of unintended pregnancies, and suggests a need for the integration of FP counselling into HIV care at all critical time-points.

Keywords: Contraceptives, Family planning counselling, HIV positive women, Postnatal, Antenatal care, Delivery

\footnotetext{
* Correspondence: jmatovu@musph.ac.ug

†Juliet Nabirye and Joseph KB Matovu contributed equally to the writing of this article.

${ }^{1}$ Department of Disease Control and Environmental Health, Makerere University School of Public Health, P.O. Box 7072, Kampala, Uganda

${ }^{2}$ Busitema University Faculty of Health Sciences, Mbale, Uganda
}

(c) The Author(s). 2020 Open Access This article is licensed under a Creative Commons Attribution 4.0 International License, which permits use, sharing, adaptation, distribution and reproduction in any medium or format, as long as you give appropriate credit to the original author(s) and the source, provide a link to the Creative Commons licence, and indicate if changes were made. The images or other third party material in this article are included in the article's Creative Commons licence, unless indicated otherwise in a credit line to the material. If material is not included in the article's Creative Commons licence and your intended use is not permitted by statutory regulation or exceeds the permitted use, you will need to obtain permission directly from the copyright holder. To view a copy of this licence, visit http://creativecommons.org/licenses/by/4.0/ The Creative Commons Public Domain Dedication waiver (http://creativecommons.org/publicdomain/zero/1.0/) applies to the data made available in this article, unless otherwise stated in a credit line to the data. 


\section{Introduction}

Women of reproductive age account for about half of people living with Human Immunodeficiency Virus (HIV) globally [1]. Preventing unintended pregnancies among women living with HIV is one of the four comprehensive approaches for confronting unwanted pregnancy among People Living With HIV/AIDS (PLWHA), an approach that was adopted by the World Health Organization (WHO) to promote and prevent the transmission of HIV from mothers to their babies [2]. Provision of appropriate counselling and support as well as contraceptives to women living with HIV to meet their family planning needs is a cost-effective intervention to prevent mother-to-child transmission of HIV [3]. However, only a handful of women living with HIV have taken any credible steps to stop unplanned pregnancies partly because many women do not receive such information and support from the health providers.

In many African countries, many women are at risk for HIV infection and unintended pregnancy at the same time [4, 5]. For instance, in Uganda, women not only have high HIV prevalence [6] but also report high fertility levels [7]; with women living with HIV (WLHIV) reporting equally high levels of unintended pregnancy ranging from 51 to $84 \%[8,9]$. In Malawi, one study found that only $51.2 \%$ of WLHIV used some form of contraception [8], suggesting that up to $49 \%$ of WLHIV were at risk of getting unintended pregnancies. Similar findings were reported in another study conducted in Ethiopia which found a contraceptive prevalence rate of $30.2 \%$ [10], suggesting a high risk of unintended pregnancy. Indeed, a recent systematic review and metaanalysis of unintended pregnancy among WLHIV in sub-Saharan Africa found a pooled proportion of unintended pregnancy of $55.9 \%$ with the magnitude of unwanted and mistimed pregnancy in six studies ranging from 14 to $59 \%$ and 9 to $47.2 \%$, respectively [11]. These studies show high rates of unwanted pregnancies for WLHIV implying that the unintended pregnancies could be substantially reduced if women used modern contraception.

Several reasons have been advanced to explain the low use of contraception among WLHIV including fears of the likely interaction between hormonal contraceptive methods and antiretroviral therapy [12], fear of side effects and the lack of social support [13]. Although there is evidence that receipt of family planning (FP) counselling can increase uptake of contraceptives [14], there are indications that many women go through the health system without receiving any form of FP counselling. For example, a study conducted among women attending antenatal care in Rwanda found that only $17 \%$ of pregnant women received any form of FP counselling on contraception [15]. In a study conducted among mothers in western Uganda, it was discovered that current users of FP methods could have been higher if village health teams counselled mothers and at the same time offered alternative contraceptive methods alternative contraceptive methods [16]. A similar study done among HIV positive women in Nigeria found that although women had knowledge of contraceptives, the percentage of women using any form of contraception was as low as $36 \%$ [17]. Collectively, these studies suggest that few women receive FP counselling, resulting in very low use of contraceptive services among pregnant women. However, most of these studies were conducted among pregnant women in the general population and not among WLHIV in particular. Besides, only a handful of studies have sought to determine what proportion of WLHIV miss FP counselling when they interface with the healthcare system. This study sought to: a) determine the proportion of WLHIV who missed the opportunity to receive $\mathrm{FP}$ counselling, and $\mathrm{b}$ ) assess the effect of receiving FP counselling on current use of modern contraceptives in order to inform the provision of FP counselling to pregnant WLHIV who access health services during antenatal care, delivery or postnatal care.

\section{Methods}

Data were drawn from a quantitative national crosssectional survey of WLHIV receiving HIV care at 245 HIV clinics in Uganda. The survey objectives were to: a) assess the unmet need for FP and b) determine the uptake of other reproductive health services including cervical cancer screening [18]. Questions relating to pregnancy history, use of FP services, and whether or not women had ever received any form of FP counselling were administered to all respondents who consented to participate in the survey using interviewer-administered questionnaires. Women who reported that they had ever given birth were asked if they were currently pregnant, and if so, whether or not they wanted to get pregnant within the past two years preceding their pregnancy or to delay the pregnancy for two or more years. Similarly, women who were not currently pregnant (but who had ever been pregnant) were asked if they wanted to become pregnant with their most recent pregnancy during the two years preceding the pregnancy or to delay the pregnancy for two or more years. Women who were pregnant at the time of interview or whose last pregnancy was before this interview but who wanted to delay their pregnancy for two or more years were termed as those with 'intention to become pregnant in the future'.

\section{Study sites}

Data for the primary survey were collected at 245 public and private HIV clinics across five geographical regions in Uganda (Central, Northern, Eastern, Western, and 
Kampala). Kampala, which is the capital city of Uganda, was considered as a separate region owing to its uniqueness. The health facilities were selected from public and private facilities across several levels of service delivery; hospitals and lower level health centers (HCIV, HCIII, and $\mathrm{HCII}$ ) that had HIV care clinics and had a minimum patient volume that was considered for their eligibility to be in the sampling frame.

\section{Survey measures}

This analysis was restricted to WLHIV who were not currently pregnant and who did not want to become pregnant in the future. We obtained data on sociodemographic characteristics, disclosure of HIV status to sexual partner, relationship status, use of antenatal care (ANC) services and delivery at a health facility; receipt of post-natal services, prior and current use of modern contraception and pregnancy history. Women were asked if they received any form of FP counselling when they interfaced with the health facility, and if they responded in the affirmative, they were asked at what point they received FP counselling, to determine if it was during ANC, immediately after delivery or during post-natal care. Women were also asked if they were currently using any of the following FP methods: pills, injectable, implant, intra-uterine device, female sterilization, vasectomy (by their male partners) or condom use for FP purposes. Women were considered to have received FP counselling if, at ANC, during delivery or post-natal care, they reported that they received information about FP methods and choices and/or discussed FP issues with a health provider. A missed opportunity for FP counselling was defined as a woman's clinic visit at which a staff member at the health facility did not provide any FP counselling. Women who reported that they did not receive such information or discussion on FP at any of the three visits were considered to have a missed opportunity for FP.

We used responses on household possessions to create an index representing a wealth proxy for the respondents interviewed. The list of household assets probed for included a radio, television set, bicycle, motorcycle, own/ family home, cell phone, regular (landline) phone, computer, income generating business, indoor bathroom, running water either inside the house or inside the compound of your house, electricity, car, generator and solar electricity. To construct the socio-economic status (SES) index, each household item was assigned a weight ascertained through principal components analysis. Then, the scores were standardized in relation to a standard normal distribution with a mean of zero and a standard deviation of one. The scores on household possessions were then summed up and individuals were ranked and sub-divided into wealth quintiles, depending on their scores, with each quintile containing $20 \%$ of the participants. The SES index was divided into five categories, namely: Lowest, second, middle, fourth and highest wealth quintile.

\section{Data analysis}

Analyses were done on 2760 women to provide descriptive statistics for women's socio-demographic characteristics. The key variables of FP counselling were determined as proportions. The primary outcome was receiving FP counselling at ANC, delivery or at postnatal care (PNC). Receipt of FP counselling was determined by women's socio-demographic characteristics. To determine the association between receipt of FP counselling and current use of modern contraception, we used prevalence ratio (PR) as the measure of association. Condom use was excluded in the final model because it tends to overestimate the modern contraception uptake and it is not reliable as a method of contraception if not used consistently and correctly.

\section{Results \\ Respondents' characteristics}

Table 1 shows the socio-demographic characteristics of the 2760 women who were included in the analysis. Nearly half $(46 \%, n=1284)$ were aged $30-39$ years, with the Eastern region having slightly more than half of the women (52.1\%) aged 30-39 years. More than half of the respondents $(58 \%, n=1600)$ were married, with the highest proportion of married HIV-positive women reported in the Eastern region (66.7\%) followed by the Western region $(63.1 \%)$ and Kampala region $(58 \%)$ in that order. About a quarter of the women $(24.3 \%, n=$ 670) were in a relationship but not married, with the highest proportion reported in the Central region (36.4\%), Kampala region (32\%) and the Northern region (27.3\%) in that order. More than half of the women $(57.4 \%, n=1585)$ had primary education while $24 \%(n=$ 656) had secondary education with the Western region (65.1\%), the Central region (60.4\%) and the Northern region (59\%) having the highest proportion of women with primary education. It is important to note that nearly a quarter $(24.6 \%)$ of women in the Northern region had no education.

About 43\% ( $n=1180)$ of women were in the lowest or second lowest wealth quintile with women in the Northern region (65\%), those in the Eastern region (51.4\%) and those in the Western region of Uganda (46.5\%) more likely to be in the lowest or second lowest wealth quintile than women in other regions. More than half of women in Kampala region (53.3\%) were in the highest wealth quintile while only a small proportion of women in the other regions (5.4-16.9\%) were in this category.

Forty-one per cent $(n=1122)$ of the respondents lived within less than $4 \mathrm{~km}$ to a health facility in all the regions with Kampala having more than half of 
Table 1 Socio-demographic characteristics of 2760 HIV-positive women enrolled in the main survey

\begin{tabular}{|c|c|c|c|c|c|c|}
\hline \multirow[b]{2}{*}{ Characteristic } & \multirow[b]{2}{*}{$\begin{array}{l}\text { Total, } \boldsymbol{N}=2760 \\
(\%)\end{array}$} & \multicolumn{5}{|l|}{ Region } \\
\hline & & $\begin{array}{l}\text { Kampala, } \boldsymbol{N}=525 \\
(\%)\end{array}$ & $\begin{array}{l}\text { Central, } \boldsymbol{N}=533 \\
\text { (\%) }\end{array}$ & $\begin{array}{l}\text { Eastern, } \boldsymbol{N}=574 \\
\text { (\%) }\end{array}$ & $\begin{array}{l}\text { Western, } \boldsymbol{N}=550 \\
(\%)\end{array}$ & $\begin{array}{l}\text { Northern, } \boldsymbol{N}=578 \\
(\%)\end{array}$ \\
\hline \multicolumn{7}{|l|}{ Age } \\
\hline $15-24$ & $240(8.7)$ & $71(13.5)$ & $45(8.4)$ & $32(5.6)$ & $43(7.8)$ & $49(8.5)$ \\
\hline $25-29$ & $420(15.2)$ & $105(20)$ & $77(14.4)$ & $73(12.7)$ & $86(15.6)$ & 79 (13.7) \\
\hline $30-39$ & $1284(46.5)$ & $239(45.5)$ & $252(47.3)$ & $299(52.1)$ & $255(46.4)$ & $239(41.3)$ \\
\hline $40-49$ & $816(29.6)$ & $110(21)$ & $159(29.8)$ & $170(29.6)$ & $166(30.2)$ & $211(36.5)$ \\
\hline \multicolumn{7}{|l|}{ Health Facility of Enrolment } \\
\hline Hospital & $810(29.4)$ & $97(18.5)$ & $163(30.8)$ & $159(27.7)$ & $178(32.5)$ & $213(36.9)$ \\
\hline HC IV & $850(30.9)$ & $47(9.0)$ & $140(26.4)$ & $234(40.8)$ & $213(38.9)$ & $216(37.4)$ \\
\hline $\mathrm{HC} \|$ & $838(30.4)$ & $228(43.4)$ & $195(36.8)$ & $137(23.9)$ & $139(25.4)$ & $139(24.0)$ \\
\hline $\mathrm{HC} \|$ & $200(7.3)$ & $139(26.5)$ & $1(0.2)$ & $37(6.4)$ & $18(3.3)$ & $5(0.9)$ \\
\hline Private health unit & $45(1.6)$ & $14(2.7)$ & $24(4.5)$ & $7(1.2)$ & $0(0.0)$ & $0(0.0)$ \\
\hline Others & $12(0.4)$ & $0(0.0)$ & $7(1.3)$ & $0(0.0)$ & $0(0.0)$ & $5(0.9)$ \\
\hline \multicolumn{7}{|l|}{ Religion } \\
\hline Catholic & $1159(42.0)$ & $178(33.9)$ & $233(43.7)$ & $171(29.8)$ & $230(41.8)$ & $347(60.0)$ \\
\hline Anglican / Protestant & $874(31.7)$ & $141(26.9)$ & $156(29.3)$ & $223(38.9)$ & $212(38.5)$ & $142(24.6)$ \\
\hline Moslem & $323(11.7)$ & $101(19.2)$ & $72(13.5)$ & $85(14.8)$ & $22(4.0)$ & $43(7.4)$ \\
\hline $\begin{array}{l}\text { Pentecostal / Born Again / } \\
\text { Evangelical }\end{array}$ & $339(12.3)$ & $92(17.5)$ & $56(10.5)$ & $90(15.7)$ & $61(11.1)$ & $40(6.9)$ \\
\hline Others Religions & $57(2.3)$ & $12(2.3)$ & $15(2.8)$ & $5(0.9)$ & $20(3.6)$ & $5(0.9)$ \\
\hline \multicolumn{7}{|l|}{ Marital status } \\
\hline Never married & $39(1.4)$ & $8(1.5)$ & $1(0.2)$ & $8(1.4)$ & $9(1.6)$ & $13(2.2)$ \\
\hline In relationship but not married & $670(24.3)$ & $168(32.0)$ & $194(36.4)$ & $77(13.4)$ & $73(13.3)$ & $158(27.3)$ \\
\hline Married & $1600(58.0)$ & $301(57.3)$ & $258(48.4)$ & $383(66.7)$ & $347(63.1)$ & $311(53.8)$ \\
\hline Divorced/separated & $264(9.6)$ & $36(6.9)$ & $52(9.8)$ & $54(9.4)$ & $68(12.4)$ & $54(9.3)$ \\
\hline Widowed & $187(6.8)$ & $12(2.3)$ & $28(5.3)$ & $52(9.1)$ & $53(9.6)$ & $42(7.3)$ \\
\hline \multicolumn{7}{|l|}{ Education $^{\mathrm{a}}$} \\
\hline No education & $453(16.4)$ & $40(7.6)$ & $85(15.9)$ & $87(15.2)$ & $99(18.0)$ & $142(24.6)$ \\
\hline Primary & $1585(57.4)$ & $241(45.9)$ & $322(60.4)$ & $323(56.3)$ & $358(65.1)$ & $341(59)$ \\
\hline Secondary & $656(23.8)$ & 208 (39.6) & $119(22.3)$ & $160(27.9)$ & $91(16.5)$ & $78(13.5)$ \\
\hline More than secondary & $58(2.1)$ & $36(6.9)$ & $5(0.9)$ & $4(0.7)$ & $1(0.2)$ & $12(2.1)$ \\
\hline Missing & $8(0.3)$ & $0(0.0)$ & $2(0.4)$ & $0(0.0)$ & $1(0.2)$ & $5(0.9)$ \\
\hline \multicolumn{7}{|l|}{ Wealth quintile } \\
\hline Lowest & $623(22.6)$ & $13(2.5)$ & $105(19.7)$ & $153(26.7)$ & $141(25.6)$ & $211(36.5)$ \\
\hline Second & $557(20.2)$ & $23(4.4)$ & $112(21.0)$ & $142(24.7)$ & $115(20.9)$ & $165(28.5)$ \\
\hline Middle & $537(19.5)$ & $38(7.2)$ & $107(20.1)$ & $147(25.6)$ & $129(23.5)$ & $116(20.1)$ \\
\hline Fourth & $541(19.6)$ & $171(32.6)$ & $119(22.3)$ & $84(14.6)$ & $112(20.4)$ & $55(9.5)$ \\
\hline Highest & $502(18.2)$ & $280(53.3)$ & $90(16.9)$ & $48(8.4)$ & $53(9.6)$ & $31(5.4)$ \\
\hline \multicolumn{7}{|l|}{ Owns a radio } \\
\hline No & $1035(37.5)$ & $191(36.4)$ & $157(29.5)$ & $227(39.5)$ & $203(36.9)$ & $257(44.5)$ \\
\hline Yes & $1725(62.5)$ & $334(63.6)$ & $376(70.5)$ & $347(60.5)$ & $347(63.1)$ & $321(55.5)$ \\
\hline \multicolumn{7}{|l|}{ Owns a Television } \\
\hline No & $2092(75.8)$ & $182(34.7)$ & $404(75.8)$ & $501(87.3)$ & 477 (86.7) & $528(91.3)$ \\
\hline Yes & $668(24.2)$ & $343(65.3)$ & $129(24.2)$ & $73(12.7)$ & 73 (13.3) & $50(8.7)$ \\
\hline
\end{tabular}


Table 1 Socio-demographic characteristics of 2760 HIV-positive women enrolled in the main survey (Continued)

\begin{tabular}{|c|c|c|c|c|c|c|}
\hline \multirow[b]{2}{*}{ Characteristic } & \multirow[b]{2}{*}{$\begin{array}{l}\text { Total, } \boldsymbol{N}=2760 \\
(\%)\end{array}$} & \multicolumn{5}{|l|}{ Region } \\
\hline & & $\begin{array}{l}\text { Kampala, } \boldsymbol{N}=525 \\
(\%)\end{array}$ & $\begin{array}{l}\text { Central, } \boldsymbol{N}=533 \\
(\%)\end{array}$ & $\begin{array}{l}\text { Eastern, } \boldsymbol{N}=574 \\
(\%)\end{array}$ & $\begin{array}{l}\text { Western, } \boldsymbol{N}=550 \\
(\%)\end{array}$ & $\begin{array}{l}\text { Northern, } \boldsymbol{N}=578 \\
(\%)\end{array}$ \\
\hline \multicolumn{7}{|c|}{ Owns a Cell phone } \\
\hline No & $559(20.3)$ & $38(7.2)$ & $95(17.8)$ & $138(24.0)$ & $121(22.0)$ & $167(28.9)$ \\
\hline Yes & $2201(79.7)$ & $487(92.8)$ & $438(82.2)$ & $436(76.0)$ & $429(78.0)$ & $411(71.1)$ \\
\hline \multicolumn{7}{|c|}{ Proximity (in Km) to health facility } \\
\hline $1-4$ & $1122(41.0)$ & $267(51.0)$ & $227(42.7)$ & $233(40.8)$ & 179 (32.8) & $216(38.2)$ \\
\hline $5-9$ & $653(23.8)$ & $108(20.6)$ & $120(22.6)$ & $137(24.0)$ & $116(21.2)$ & $172(30.4)$ \\
\hline $10-15$ & $330(12.1)$ & $57(10.9)$ & $47(8.9)$ & $58(10.2)$ & $90(16.5)$ & $78(13.8)$ \\
\hline $15+$ & $633(23.1)$ & $92(17.6)$ & $137(25.8)$ & $143(25)$ & $161(29.5)$ & $100(17.7)$ \\
\hline \multicolumn{7}{|c|}{ On antiretroviral therapy } \\
\hline No & $82(3.0)$ & $27(5.2)$ & $0(0.0)$ & $10(1.7)$ & $27(4.9)$ & $18(3.1)$ \\
\hline Yes & $2667(97.0)$ & $497(94.8)$ & $529(100.0)$ & $563(98.3)$ & $523(95.1)$ & $555(96.9)$ \\
\hline \multicolumn{7}{|c|}{ Duration on ART (Years) } \\
\hline Not on ART & $251(9.5)$ & $83(16.8)$ & $57(10.8)$ & $39(7)$ & $39(7.5)$ & $33(6.0)$ \\
\hline$<1$ year & $281(10.6)$ & $56(11.3)$ & $64(12.1)$ & $54(9.7)$ & $52(10.0)$ & $55(10.1)$ \\
\hline$<2$ years & $345(13.0)$ & $71(14.4)$ & $70(13.3)$ & $59(10.6)$ & $71(13.7)$ & $74(13.5)$ \\
\hline $2+$ years & $1767(66.8)$ & $284(57.5)$ & $336(63.8)$ & $405(72.7)$ & $357(68.8)$ & $385(70.4)$ \\
\hline \multicolumn{7}{|c|}{ Disclosed HIV status to partner } \\
\hline No & $2313(84.4)$ & 367 (70.6) & $414(78.0)$ & $504(88.3)$ & $479(87.6)$ & $549(96.3)$ \\
\hline Yes & $426(15.6)$ & $153(29.4)$ & $117(22.0)$ & $67(11.7)$ & $68(12.4)$ & $21(3.7)$ \\
\hline \multicolumn{7}{|c|}{ Number of biological children } \\
\hline 0 & $724(26.2)$ & $124(23.6)$ & $175(32.8)$ & $124(21.6)$ & $175(31.8)$ & $126(21.8)$ \\
\hline 1 & $135(4.9)$ & $58(11.0)$ & $21(3.9)$ & $17(3.0)$ & $17(3.1)$ & $22(3.8)$ \\
\hline 2 & $320(11.6)$ & $101(19.2)$ & $63(11.8)$ & $44(7.7)$ & $60(10.9)$ & $52(9.0)$ \\
\hline 3 & $400(14.5)$ & $98(18.7)$ & $63(11.8)$ & $83(14.5)$ & $81(14.7)$ & $75(13.0)$ \\
\hline $4+$ & $1181(42.8)$ & $144(27.4)$ & $211(39.6)$ & $306(53.3)$ & $217(39.5)$ & $303(52.4)$ \\
\hline \multicolumn{7}{|c|}{ Received any FP Counselling } \\
\hline No & $656(23.8)$ & $154(29.3)$ & $145(27.2)$ & $118(20.6)$ & $100(18.2)$ & $139(24.0)$ \\
\hline Yes & $2104(76.2)$ & $371(70.7)$ & $388(72.8)$ & $456(79.4)$ & $450(81.8)$ & $439(76.0)$ \\
\hline \multicolumn{7}{|c|}{ Number of FP Counselling Visits } \\
\hline 0 & $656(23.8)$ & $154(29.3)$ & $145(27.2)$ & $118(20.6)$ & $100(18.2)$ & $139(24.0)$ \\
\hline 1 & $502(18.2)$ & $118(22.5)$ & $137(25.7)$ & $56(9.8)$ & $77(14.0)$ & $114(19.7)$ \\
\hline 2 & $688(24.9)$ & $134(25.5)$ & $156(29.3)$ & $121(21.1)$ & $113(20.5)$ & $164(28.4)$ \\
\hline 3 & $914(33.1)$ & $119(22.7)$ & $95(17.8)$ & $279(48.6)$ & $260(47.3)$ & $161(27.9)$ \\
\hline
\end{tabular}

${ }^{a}$ Education categories refer to the highest level of education attended, whether or not that level was completed

the respondents living within this distance to a health facility. Majority $(97 \%, n=2667)$ of the respondents were on antiretroviral therapy (ART) with slightly more than two-thirds (66.8\%) having been on ART for more than two years. The Central region (100\%), Eastern region $(98.3 \%)$ and the Northern region (96.9\%) recorded the highest proportion of HIVpositive women on ART. Only $15.6 \%(n=426)$ of HIV-positive women reported that they disclosed their HIV sero-positive status to their sexual partners, and this trend was observed across all the other regions. Forty-three per cent $(n=1181)$ of women had four or more $(4+)$ biological children, with the proportion of those reporting $4+$ biological children recorded in the Eastern (53.3\%) and the Northern regions (52.4\%) while Kampala region (27.4\%) had the lowest proportion of women with $4+$ biological children. 
Table 2 Percentage of women in HIV care who are not currently pregnant and would not like to become pregnant that received FP counselling overall; during ANC visit, during delivery or during Post-Natal Care

\begin{tabular}{|c|c|c|c|c|}
\hline \multirow[t]{2}{*}{ Characteristic } & \multicolumn{4}{|l|}{$\boldsymbol{N}=2760$} \\
\hline & $\overline{\mathrm{ANC}}$ & Delivery & Post-natal Care & Any FP counselling \\
\hline Total & $1715(62.1)$ & $1629(59.0)$ & $1276(46.2)$ & $2104(76.2)$ \\
\hline \multicolumn{5}{|l|}{ Age-group } \\
\hline $15-24$ & $138(57.5)$ & $134(55.8)$ & $106(44.2)$ & $172(71.7)$ \\
\hline $25-29$ & $259(61.7)$ & $267(63.6)$ & $206(49.0)$ & $328(78.1)$ \\
\hline $30-39$ & $822(64.0)$ & $779(60.7)$ & $623(48.5)$ & $1001(78.0)$ \\
\hline $40-49$ & $496(60.8)$ & $449(55.0)$ & $341(41.8)$ & $603(73.9)$ \\
\hline \multicolumn{5}{|l|}{ Region } \\
\hline Kampala & $278(53.0)$ & $280(53.3)$ & $185(35.2)$ & $371(70.7)$ \\
\hline Central & $268(50.3)$ & $310(58.2)$ & $156(29.3)$ & $388(72.8)$ \\
\hline Eastern & $420(73.2)$ & $362(63.1)$ & $353(61.5)$ & $456(79.4)$ \\
\hline Western & $365(66.4)$ & $365(66.4)$ & $353(64.2)$ & $450(81.8)$ \\
\hline Northern & $384(66.4)$ & $312(54.0)$ & $229(39.6)$ & $439(76.0)$ \\
\hline \multicolumn{5}{|l|}{ Enrolment Health Facility } \\
\hline Hospital & $479(59.1)$ & $446(55.1)$ & $349(43.1)$ & $592(73.1)$ \\
\hline HC IV & $578(68.0)$ & $543(63.9)$ & $466(54.8)$ & $678(79.8)$ \\
\hline $\mathrm{HC} I I$ & $510(60.9)$ & $499(59.5)$ & $354(42.2)$ & $651(77.7)$ \\
\hline $\mathrm{HC} \|$ & $111(55.5)$ & $104(52.0)$ & $74(37.0)$ & $135(67.5)$ \\
\hline Private health unit & $28(62.2)$ & $29(64.4)$ & $29(64.4)$ & $37(82.2)$ \\
\hline Others & $6(50.0)$ & $5(41.7)$ & $2(16.7)$ & $7(58.3)$ \\
\hline \multicolumn{5}{|l|}{ Religion } \\
\hline Catholic & $718(61.9)$ & $670(57.8)$ & $524(45.2)$ & $881(76.0)$ \\
\hline Anglican / Protestant & $545(62.4)$ & $528(60.4)$ & $434(49.7)$ & $676(77.3)$ \\
\hline Moslem & $208(64.4)$ & $204(63.2)$ & $142(44.0)$ & $248(76.8)$ \\
\hline Pentecostal & $208(61.4)$ & $196(57.8)$ & $156(46.0)$ & $256(75.5)$ \\
\hline Others & $33(57.9)$ & $28(49.1)$ & $18(31.6)$ & $39(68.4)$ \\
\hline \multicolumn{5}{|l|}{ Marital status } \\
\hline Never married & $21(53.8)$ & $21(53.8)$ & $16(41.0)$ & $27(69.2)$ \\
\hline In relationship but not married & $371(55.4)$ & $356(53.1)$ & $231(34.5)$ & $464(69.3)$ \\
\hline Married & $1067(66.7)$ & $1001(62.6)$ & $836(52.3)$ & $1277(79.8)$ \\
\hline Divorced/separated & $154(58.3)$ & $160(60.6)$ & $119(45.1)$ & $209(79.2)$ \\
\hline Widowed & $102(54.5)$ & $91(48.7)$ & $74(39.6)$ & $127(67.9)$ \\
\hline \multicolumn{5}{|l|}{ Education } \\
\hline No education & $263(58.1)$ & $241(53.2)$ & $203(44.8)$ & $325(71.7)$ \\
\hline Primary & $987(62.3)$ & $943(59.5)$ & $734(46.3)$ & $1219(76.9)$ \\
\hline Secondary & $428(65.2)$ & $406(61.9)$ & $314(47.9)$ & $516(78.7)$ \\
\hline More than secondary & $35(60.3)$ & $37(63.8)$ & $24(41.4)$ & $41(70.7)$ \\
\hline Missing & $2(25.0)$ & $2(25.0)$ & $1(12.5)$ & $3(37.5)$ \\
\hline \multicolumn{5}{|l|}{ Wealth quintile } \\
\hline Lowest & $408(65.5)$ & $352(56.5)$ & $306(49.1)$ & $487(78.2)$ \\
\hline Second & $379(68,0)$ & $324(58.2)$ & $270(48.5)$ & $427(76.7)$ \\
\hline Middle & $316(58.8)$ & $332(61.8)$ & $265(49.3)$ & $410(76.4)$ \\
\hline Fourth & $329(60.8)$ & $324(59.9)$ & $237(43.8)$ & $413(76.3)$ \\
\hline
\end{tabular}


Table 2 Percentage of women in HIV care who are not currently pregnant and would not like to become pregnant that received FP counselling overall; during ANC visit, during delivery or during Post-Natal Care (Continued)

\begin{tabular}{|c|c|c|c|c|}
\hline \multirow[t]{2}{*}{ Characteristic } & \multicolumn{4}{|l|}{$\boldsymbol{N}=2760$} \\
\hline & ANC & Delivery & Post-natal Care & Any FP counselling \\
\hline Highest & $283(56.4)$ & $297(59.2)$ & $198(39.4)$ & $367(73.1)$ \\
\hline \multicolumn{5}{|c|}{ On antiretroviral therapy } \\
\hline No & $49(59.8)$ & $36(43.9)$ & $37(45.1)$ & $56(68.3)$ \\
\hline Yes & $1661(62.3)$ & $1588(59.5)$ & $1235(46.3)$ & $2041(76.5)$ \\
\hline \multicolumn{5}{|c|}{ Duration on ART (Years) ${ }^{a}$} \\
\hline Not on ART & $125(49.8)$ & $122(48.6)$ & $89(35.5)$ & $175(69.7)$ \\
\hline$<1$ year & $154(54.8)$ & $144(51.2)$ & $116(41.3)$ & $201(71.5)$ \\
\hline$<2$ years & $224(64.9)$ & $204(59.1)$ & $164(47.5)$ & $268(77.7)$ \\
\hline $2+$ years & $1145(64.8)$ & $1106(62.6)$ & $857(48.5)$ & $1382(78.2)$ \\
\hline \multicolumn{5}{|c|}{ Disclosed HIV status to partner } \\
\hline No & $1499(64.8)$ & $1403(60.7)$ & $1130(48.9)$ & $1798(77.7)$ \\
\hline Yes & $200(46.9)$ & $211(49.5)$ & $136(31.9)$ & $287(67.4)$ \\
\hline \multicolumn{5}{|c|}{ Number of biological children } \\
\hline 0 & $387(53.5)$ & $382(52.8)$ & $289(39.9)$ & $505(69.8)$ \\
\hline 1 & $65(48.1)$ & $63(46.7)$ & $42(31.1)$ & $88(65.2)$ \\
\hline 2 & $201(62.8)$ & $193(60.3)$ & $154(48.1)$ & $254(79.4)$ \\
\hline 3 & $256(64)$ & $245(61.3)$ & $181(45.3)$ & $309(77.3)$ \\
\hline $4+$ & $806(68.2)$ & $746(63.2)$ & $610(51.7)$ & $948(80.3)$ \\
\hline
\end{tabular}

${ }^{\mathrm{a} E x p r e s s e d ~ o u t ~ o f ~ t h o s e ~ w h o ~ r e p o r t e d ~ t h a t ~ t h e y ~ w e r e ~ o n ~ A R T ~}$

\section{Receipt of FP counselling}

Table 2 shows the percentage of women in HIV care that were not currently pregnant and who did not want to become pregnant in the future, stratified by whether or not they received any FP counselling; and if so, whether or not they received FP counselling during ANC visit, at the time of delivery or at the post-natal care (PNC) visit. Slightly more than three quarters (76\%) of the women reported that they received FP counselling at any of the three points of care (ANC, delivery and PNC). Receipt of FP counselling was highest at ANC $(62.1 \%, n=1715)$ but was slightly lower at the time of delivery $(59 \%, n=1629)$ and at the PNC visit $(46.2 \%, n=$ 1276). By region, the proportion of women who received FP counselling was highest in the Western region $(81.8 \%)$, the Eastern $(79.4 \%)$ and the Northern region (76\%) but was lowest in the Central region $(72.8 \%)$ and Kampala (70.8\%) (Table 1). Approx. 58\% of the women were found to have received FP counselling at two (24.9\%) or three visits (33.1\%), with wide variations across regions (Table 1 ).

Table 2 also shows that receipt of FP counselling differed by age, region of residence, point of delivery, health facility where women were enrolled, and ART status. At least $60 \%$ of all women across all age groups received FP counselling during ANC with the highest proportion recorded among those aged 30 to 39 years.
At the time of delivery, women aged 25-29 were the highest recipients of FP counselling at nearly $64 \%$. Younger women below 24 years and women aged 40 or more years were the lowest recipients of FP counselling at post-natal care. The Western region had the highest proportion of women who received any form of FP counselling at $82 \%$. Kampala and Central region had the lowest proportion of women receiving FP counselling during ANC with nearly half of women reporting that they did not receive any form of FP counselling during contact with a healthcare provider.

At the point of delivery, the Northern region and Kampala recorded at least half of the women receiving FP counselling while the other half missed out on this service. During postnatal care, the Northern region registered the lowest proportion of women who received FP counselling at $40 \%$. Provision of FP counselling was highest at health Centre IIs and IVs with approximately $80 \%$ of the women receiving FP counselling at these facilities. A higher proportion of married women and women educated up to secondary level received FP counselling across the three points of care than unmarried and divorced women although PNC was the least used point for FP counselling. Women on ART were beneficiaries of FP counselling across the three levels of care with $62 \%$ of them obtaining FP counselling at ANC, $60 \%$ during delivery and $46 \%$ at postnatal care. A higher 
proportion of women ( $80 \%$ or higher) who had been on ART for two years and those with four or more biological children received FP counselling more than their counterparts across the three points of care.

\section{Association between receipt of any FP counselling and current use of modern contraception}

Table 3 shows the association between receipt of any FP counselling and current use of modern contraception among women who were not pregnant and who did not want to have any other children in the future. Overall, current use of a modern contraceptive method was $21 \%$ higher among women who received any FP counselling compared to those who did not (adjusted [adj.] PR: 1.21; $95 \%$ confidence interval $[\mathrm{CI}]: 1.10,1.33)$. Current use of modern contraception was also $28 \%$ higher among women who had attained more than secondary level of education compared to those with primary level of education and $28 \%$ higher among those who had spent more than two years on ART. Current use of modern contraceptive use was also more than $30 \%$ higher among women who had two or more biological children than their counterparts. We found that current use of modern contraception increased with the increasing number of FP counselling visits but this analysis was restricted to the bivariate analysis due to collinearity between 'any FP counselling', the primary outcome, and 'number of FP counselling visits'.

\section{Discussion}

Our study of missed opportunities for FP counselling among HIV-positive women receiving HIV care in Uganda highlights two important findings: a) up to $24 \%$ of HIVpositive women who interfaced with the healthcare system when they were pregnant, at the time of delivery or at the post-natal care visit did not receive any form of FP counselling; and b) receipt of any FP counselling at any of the three time points is associated with current use of modern contraception. We found that receipt of FP counselling was higher during ANC (62.1\%), declined at the time of delivery (59\%) and was lowest at the post-natal care visit (46.2\%). These findings imply that $38 \%$ of women missed FP counselling at ANC; $41 \%$ missed FP counselling at the time of delivery, while 54\% missed FP counselling at the post-natal care visit. Similar findings have been reported elsewhere $[19,20]$. Venkataramani et al. found that only $0.3 \%$ of parents were counseled about FP during 4261 preventive care visits [19] while Moore et al. found that $61 \%$ of all postpartum women across the 21 countries studied had an unmet need for FP [20]. Collectively, our findings highlight a missed opportunity for FP counselling among HIV-positive women who have an unmet need for limiting childbirth and suggest a need for full-scale integration of FP counselling at all critical time-points, but most importantly at the post-natal care visit.
The fact that FP counselling was highest at ANC but lowest during post-natal services raises serious public health concerns. It shows that a significant proportion of HIV positive women who interface with the health system at the post-natal care visit are not provided with FP counselling yet they are at an increased risk for unwanted and short-interval pregnancies [21]. Although fewer women attend post-natal care services when compared to those who attend ANC [22], possibly due to a perception of having received sufficient information about childcare and the management of post-natal complications at ANC [23, 24], this small number of women should still be targeted with adequate FP information when they come for post-natal care services. Our findings point to the fact that the more women interface with the health system, the more they are likely to obtain FP counselling. This is similar to a study done in Pakistan, where the use of contraception increased with the number of ANC visits from $8 \%$ among women who did not make any antenatal visit to $32 \%$ of women who made four ANC visits [25].

Our findings have implications for the provision of contraceptive services to pregnant women across countries. For instance, a study of post-partum contraception among 250 women in Edinburg found that nearly all women (96.7\%) who attended post-natal care services did not want to have a baby in the following year but up to $35.2 \%$ of them did not know what contraception to use post-natal [26]. Indeed, evidence shows that a significant proportion of women are willing to use contraception post-natal only that they lack the information needed to make informed contraceptive decisions [26, 27]. Thus, the lack of FP counselling, acts as a missed opportunity to prevent unintended pregnancy and shortinterval pregnancies. The low provision of FP counselling to women during delivery may not be surprising given that at that time, the woman is more concerned about safe delivery or the need to return home following a safe delivery than issues of child spacing or limiting childbirth. This observation is in agreement with previous studies that show that contraceptive counselling during delivery may not be very effective because women are in a hurry to go home [16].

The finding that FP counselling was associated with current use of modern contraceptive methods is in agreement with previous studies in which women that received FP messages from a health worker had higher odds of using contraceptives than their counterparts and suggest an opportunity to reduce the unmet need for FP services through counselling $[28,29]$. Studies also show that in programs that focus on HIV care and treatment, adherence counselling offers an exceptional chance to address preventive health recommendations, including FP [29]. The continued use of modern FP methods by 
Table 3 Factors associated with receipt of any FP Counselling and current use of modern contraception (excluding condom use)

\begin{tabular}{|c|c|c|c|c|}
\hline \multirow[b]{2}{*}{ Background characteristic } & \multicolumn{2}{|l|}{ Bivariate } & \multicolumn{2}{|l|}{ Multivariable } \\
\hline & PR $(95 \% \mathrm{Cl})$ & $\boldsymbol{p}$-value & PR $(95 \% \mathrm{Cl})$ & p-value \\
\hline \multicolumn{5}{|c|}{ Received any FP counselling } \\
\hline No & Ref & & Ref & \\
\hline Yes & $1.31(1.19,1.44)$ & $<0.001$ & $1.21(1.10,1.33)$ & $<0.001^{*}$ \\
\hline
\end{tabular}

Number of FP counselling visits

None $\quad$ Ref

1

2

3

Age

15-24

25-29

30-39

40-49

\section{Region}

Northern

Kampala

Central

Eastern

Western

\section{Level Health Facility}

Hospital

Health Center IV

Health Center III

Health Center II

Private Health Unit

Others

\section{Religion}

Catholic

Anglican / Protestant

Moslem

Protestant / Born Again

Other Religions

\section{Marital status}

Never married
In relationship but not married
Married
Divorced/separated
Widowed

\section{Education}

No education

Primary

Secondary

Above Secondary

$\begin{array}{ll}1.14(1.01,1.29) & 0.04 \\ 1.30(1.62,1.45) & <0.001 \\ 1.40(1.27,1.55) & <0.001\end{array}$

Ref

$1.08(0.94,1.24) \quad 0.30$

0.11

$1.11(0.98,1.25)$

0.00

$0.74(0.64,0.86)$

Ref

$1.29(1.14,1.46)$

0.00

$1.19(1.05,1.36)$

0.01

$1.49(1.33,1.66)$

0.00

$1.35(1.20,1.52)$

0.00

Ref

$1.13(1.04,1.24)$

0.01

$1.08(0.99,1.19)$

0.09

$1.16(1.01,1.33)$

0.03

$0.94(0.68,1.29)$

0.68

$1.00(0.57,1.77)$

0.99

Ref

$1.09(1.01,1.18)$

0.03

$1.03(0.92,1.15)$

0.63

$0.97(0.86,1.09)$

0.60

$0.94(0.72,1.23)$

0.64

Ref

$1.77(1.07,2.94)$

0.03

$2.11(1.28,3.49)$

0.00

$1.63(0.97,2.73)$

0.07

$1.23(0.72,2.11)$

0.45

Ref

$1.09(0.98,1.21)$

0.095

$1.13(1.01,1.27)$

0.036

$1.22(0.97,1.53)$
Ref

$1.00(0.86,1.15)$

0.97

$0.98(0.85,1.12)$

0.73

$0.67(0.58,0.79)$

0.00

Ref

$1.29(1.11,1.49)$

0.00

$1.21(1.06,1.37)$

0.00

$1.41(1.25,1.58)$

0.00

$1.31(1.16,1.48)$

0.00

Ref

$1.09(0.99,1.19)$

0.07 *

$1.05(0.96,1.15)$

0.28

$1.05(0.90,1.22)$

0.53

$0.88(0.64,1.21)$

0.44

$1.25(0.72,2.17)$

0.42

$1.02(0.94,1.11)$

0.59

$0.96(0.85,1.08)$

0.47

$0.91(0.81,1.03)$

0.13

$0.87(0.66,1.14)$

0.32

Ref

$1.38(0.82,2.34) \quad 0.23$

$1.43(0.84,2.44) \quad 0.19$

$1.50(0.89,2.53) \quad 0.13$

$1.28(0.74,2.21)$

0.38

Ref

$\begin{array}{ll}1.05(0.94,1.16) & 0.39\end{array}$

$\begin{array}{ll}1.07(0.95,1.20) & 0.27\end{array}$

$1.28(1.00,1.63) \quad 0.05^{*}$ 
Table 3 Factors associated with receipt of any FP Counselling and current use of modern contraception (excluding condom use) (Continued)

\begin{tabular}{|c|c|c|c|c|}
\hline \multirow[b]{2}{*}{ Background characteristic } & \multicolumn{2}{|l|}{ Bivariate } & \multicolumn{2}{|l|}{ Multivariable } \\
\hline & PR $(95 \% \mathrm{Cl})$ & $\boldsymbol{p}$-value & PR $(95 \%$ Cl) & p-value \\
\hline \multicolumn{5}{|l|}{ Wealth quintile } \\
\hline Lowest & Ref & & Ref & \\
\hline Second & $1.14(1.02,1.27)$ & 0.02 & $1.11(0.99,1.24)$ & 0.06 \\
\hline Middle & $1.19(1.07,1.33)$ & 0.00 & $1.12(1.01,1.25)$ & $0.04^{*}$ \\
\hline Fourth & $1.15(1.03,1.29)$ & 0.01 & $1.08(0.96,1.21)$ & 0.22 \\
\hline Highest & $1.12(1.0,1.25)$ & 0.06 & $1.05(0.92,1.19)$ & 0.49 \\
\hline \multicolumn{5}{|l|}{ Duration on ART } \\
\hline Not on ART & Ref & & & \\
\hline$<1$ year & $1.11(0.92,1.33)$ & 0.27 & $1.10(0.92,1.32)$ & 0.30 \\
\hline$<2$ years & $1.29(1.10,1.52)$ & 0.00 & $1.28(1.09,1.51)$ & $0.00^{*}$ \\
\hline $2+$ years & $1.23(1.07,1.43)$ & 0.00 & $1.28(1.10,1.48)$ & 0.00 \\
\hline \multicolumn{5}{|c|}{ Number of biological children } \\
\hline 0 & Ref & & Ref & \\
\hline 1 & $1.18(0.97,1.43)$ & 0.10 & $1.09(0.86,1.37)$ & 0.49 \\
\hline 2 & $1.47(1.29,1.66)$ & 0.00 & $1.30(1.08,1.57)$ & $0.01 *$ \\
\hline 3 & $1.51(1.34,1.7)$ & $\begin{array}{l}0.00 \\
0.00\end{array}$ & $1.37(1.14,1.65)$ & 0.00 \\
\hline $4+$ & $1.42(1.28,1.57)$ & 0.00 & $1.38(1.16,1.66)$ & 0.00 \\
\hline
\end{tabular}

HIV-infected women subsequently prevents birth of HIV-positive infants and reduces cost of Preventing Mother-To-Child Transmission (PMTCT) in addition to ensuring spaced pregnancies, which results in healthier babies, despite the mother's HIV status [30].

\section{Strengths and limitations of the study}

Our study had several limitations. For instance, although we found an association between FP counselling and current use of modern contraception, we cannot infer a causal relationship between the two. Precisely, this study cannot depict that receiving FP counselling always results in uptake of contraception due to its crosssectional nature. We also recognize that HIV-positive women who came for ANC services could have been different from other HIV-positive women who did not utilize ANC services. This affects the generalizability of the study findings to all HIV-positive women in Uganda. Besides, while we collected qualitative data about the barriers to uptake of contraceptive services among HIVpositive women as part of this study, these results were not yet available at the time of writing this paper. Therefore, we cannot fully explain why some women did not use contraception services even after receiving FP counselling. However, as our study findings show, receipt of FP counselling was associated with higher odds of current use of modern contraception suggesting that FP counselling is a key determinant of current contraceptive use among HIV-positive women. The above-mentioned limitations notwithstanding, our study addressed one of the key areas, which remains salient in the effort needed to prevent mother-to-child transmission of HIV. It shows that there is a missed opportunity for FP counselling among HIV-positive women who interface with the healthcare system, calling for a need to integrate FP counselling into HIV care at critical times during antenatal care, during delivery and when women return for post-natal services to reduce unmet need for FP among HIV-positive women.

\section{Conclusion}

In conclusion, our study shows that nearly a quarter of HIV-positive women who interface with the healthcare system while pregnant, during delivery or at the post-natal care visit miss the opportunity to be counseled about contraception, which presents a missed opportunity for prevention of unwanted and untimed pregnancies. This missed opportunity becomes even more prominent when we realize that women who received FP counselling at any of the three critical time-points were significantly more likely to report current use of modern contraception than women who did not. Given the increasing popularity of hormonal contraception methods, efforts should be directed at counselling women about the importance of contraception to avoid unwanted pregnancies and reduce mother-to-child transmission of HIV and there is a need 
to enhance FP integration into HIV care in order to increase access to contraceptives among HIV-positive women in care. We particularly recommend an improvement on provision of FP counselling to HIV-positive women who attend the postnatal care visit since it improves uptake of modern contraceptives.

\section{Abbreviations}

ANC: Antenatal Care; ART: Anti-Retroviral Therapy; FP: Family Planning; HIV: Human Immunodeficiency; PLWHIV: People Living With HIV; PMTCT: Prevention of Mother to Child Transmission; PR: Prevalence Ratio; WLHIV: Women Living with HIV

\section{Acknowledgements}

We thank all the study participants and the health centers from which the data was obtained.

We wish to acknowledge our research assistants, other members of the research team; the health workers at the facilities where data were collected, the clients who participated in this study and the District Health Officers for their invaluable support.

\section{Authors' contributions}

JKBM and JNB were involved in drafting and writing this paper, JB was the statistician and he was responsible for the overall analysis of the data. FM and RW provided technical guidance and read through the manuscript for guidance. All authors participated in the interpretation of the data, and reviewed and approved the final version of the manuscript.

\section{Funding}

This research was funded by the Uganda Ministry of Health through a Grant from the Global Fund and UNFPA. During the writing of the paper, JKBM received additional support from the National Institutes of Health Global Health Equity Scholars Fellowship Program (FIC D43TW010540) and the Africa Research Excellence Fund (RF-157-0024-F-MATOV). The funders had no role in study design, data collection and analysis, preparation of the manuscript or the decision to publish this paper.

\section{Availability of data and materials}

Data for this study is available upon reasonable request from the corresponding author.

\section{Ethics approval and consent to participate}

Makerere University School of Public Health Higher Degrees, Research and Ethics Committee and the Uganda National Council for Science and Technology approved this study. Permission to conduct the study was obtained from district and facility managers. Respondents were read an informed consent form and asked if they were willing to participate in the study. Respondents were informed that their non-willing to participate in the study would not affect their access to any of the services provided at the health facility of recruitment. Consenting women signed two copies of a written informed consent form and retained a copy for their future reference. Young HIV-positive, pregnant or ever-pregnant women aged 15 to 17 years were enrolled as emancipated minors, with a waiver of the parental or guardian consent, based on the national research guidelines. Interviews were conducted privately within or outside facility premises in seclusion to ensure confidentiality. All data provided by participants were anonymous and we ensured confidentiality of all the data collected.

\section{Consent for publication}

Not applicable.

\section{Competing interests}

The authors declare no competing interests.
Received: 4 October 2019 Accepted: 12 April 2020

Published online: 05 May 2020

\section{References}

1. UNAIDS. Global AIDS update 2016. Geneva: World Health Organization; 2016. https://www.unaids.org/en/resources/documents/2016/Global-AIDSupdate-2016. Accessed 14 Feb 2020.

2. WHO. Global health sector strategy on HIV 2016-2021. Towards ending AIDS. Geneva: World Health Organization; 2016. https:/apps.who.int/iris/ bitstream/handle/10665/246178/WHO-HIV-2016.05-eng.pdf;jsessionid= 2F7261C31434B799BAA2D68F3E06C452? sequence=1. Accessed 24 Feb 2020

3. Reynolds HW, Janowitz B, Wilcher R, Cates W. Contraception to prevent HIVpositive births: current contribution and potential cost savings in PEPFAR countries. Sex Transm Infect. 2008;84(Suppl 2):ii49-53.

4. Nakayiwa S, Abang B, Packel L, Lifshay J, Purcell DW, King R, Ezati E, Mermin J, Coutinho A, Bunnell R. Desire for children and pregnancy risk behavior among HIV-infected men and women in Uganda. AIDS Behav. 2006;10(4 Suppl):S95-104.

5. Homsy J, Bunnell R, Moore D, King R, Malamba S, Nakityo R, et al. Reproductive intentions and outcomes among women on antiretroviral therapy in rural Uganda. A prospective cohort study. PLoS One. 2009;4(1): 41-9.

6. UNAIDS. 2008 report on the global AIDS epidemic. Geneva: UNAIDS; 2008. https://www.unaids.org/sites/default/files/media_asset/jc1510_2 008globalreport_en_1.pdf. Accessed 1 Feb 2020.

7. Uganda Bureau of Statistics (UBOS) and ICF. Uganda Demographic and Health Survey 2016. Kampala and Rockville: UBOS and ICF; 2018. https:// dhsprogram.com/pubs/pdf/FR333/FR333.pdf. Accessed 1 Feb 2020.

8. GBCHealth. Family planning and HIV services: increased efficiency and impact through integration. 2012. http://archive.gbchealth.org/system/ documents/category_24/277/FP\%20\&\%20HIV\%20\%20lssue\%20BriefFormatted\%20FINAL3.pdf?1340661954. Accessed 1 Mar 2020.

9. Rispel LC, Peltzer K, Phaswana-Mafuya N, Metcalf CA, Treger L. Assessing missed opportunities for the prevention of mother-to-child HIV transmission in an Eastern Cape local service area. S Afr Med J. 2009;99(3):174-9.

10. Alene KA, Atalell KA. Contraceptive use and method preference among HIVpositive women in Amhara region, Ethiopia. BMC Womens Health. 2018; 18(1):97.

11. Feyissa TR, Harris ML, Melka AS, Loxton D. Unintended pregnancy in women living with HIV in Sub-Saharan Africa: a systematic review and meta-analysis. AIDS Behav. 2019;23(6):1431-51.

12. Pyra M, Heffron R, Mugo NR, Nanda K, Thomas KK, Celum C, et al. Effectiveness of hormonal contraception in HIV-infected women using antiretroviral therapy: a prospective study. AIDS. 2015;29(17):2353-9.

13. Kibira SP, Muhumuza C, Bukenya JN, Atuyambe LM. "I spent a full month bleeding, I thought I was going to die..." a qualitative study of experiences of women using modern contraception in Wakiso District, Uganda. PLoS One. 2015;10(11):e0141998.

14. Kennedy CE, Fonner VA, Sweat MD, Okero FA, Baggaley R, O'Reilly KR. Provider-initiated HIV testing and counselling in low-and middle-income countries: a systematic review. AIDS Behav. 2013;17(5):1571-90.

15. Allen S, Serufilira A, Gruber V, Kegeles S, Van de Perre P, Carael M, Coates TJ. Pregnancy and contraception use among urban Rwandan women after HIV testing and counseling. Am J Public Health. 1993;83(5):705-10.

16. Ayiasi RM, Muhumuza C, Bukenya J, Orach CG. The effect of prenatal counselling on postpartum family planning use among early postpartum women in Masindi and Kiryandongo districts. Uganda. Pan Afr Med J. 2015; 21:138.

17. Shehu AU, Joshua IA, Umar Z. Knowledge of contraception and contraceptive choices among human immunodeficiency virus-positive women attending antiretroviral clinics in Zaria. Nigeria.Sub-Saharan Afr J Med. 2016;3(2):84-90.

18. Wanyenze RK, Bwanika JB, Beyeza-Kashesya J, Mugerwa S, Arinaitwe J, Matovu JK, et al. Uptake and correlates of cervical cancer screening among HIV-infected women attending HIV care in Uganda. Glob Health Action. 2017;10(1):1380361.

19. Venkataramani M, Cheng TL, Solomon BS, Pollack CE. How often are parents counseled about family planning during pediatric visits? Results of a nationally representative sample. Acad Pediatr. 2017;17(5):476-8.

20. Moore Z, Pfitzer A, Gubin R, Charurat E, Elliott L, Croft T. Missed opportunities for family planning: an analysis of pregnancy risk and 
contraceptive method use among postpartum women in 21 low- and middle-income countries. Contraception. 2015;92(1):31-9.

21. Nagai M, Bellizzi S, Murray J, Kitong J, Cabral El, Sobel HL. Opportunities lost: Barriers to increasing the use of effective contraception in the Philippines. PLoS One. 2019;14(7):e0218187.

22. Gebrehiwot G, Medhanyie AA, Gidey G, Abrha K. Postnatal care utilization among urban 470 women in northern Ethiopia: cross-sectional survey. BMC Womens Health. 2018;18(1):78.

23. Watson-Jones D, Balira R, Ross DA, Weiss HA, Mabey D. Missed opportunities: poor linkage into ongoing care for HIV-positive pregnant women in Mwanza, Tanzania. PLoS One. 2012;7(7):e40091.

24. Kairania R, Gray RH, Kiwanuka N, Makumbi F, Sewankambo NK, Serwadda D, et al. Disclosure of HIV results among discordant couples in Rakai, Uganda: a facilitated couple counselling approach. AIDS Care. 2010;22(9):1041-51.

25. Agha S, Williams E. Does the antenatal care visit represent a missed opportunity for increasing contraceptive use in Pakistan? An analysis of household survey data from Sindh province. Health Policy Plann. 2015;31(3): $325-31$

26. Heller R, Cameron S, Briggs R, Forson N, Glasier A. Postpartum contraception: a missed opportunity to prevent unintended pregnancy and short inter-pregnancy intervals. J Fam Plann Reprod Health Care. 2016;42(2): 93-8.

27. Thwaites A, Logan L, Nardone A, Mann S. Immediate postnatal contraception: what women know and think. BMJ Sex Reprod Health. 2019; 45(2):111-7.

28. Makumbi F, Nakigozi G, Lutalo T, Kagayi J, Sekasanvu J, Settuba A, Serwada D, Wawer M, Gray R. Use of HIV-related services and modern contraception among women of reproductive age. Rakai Uganda. Afr J Reprod Health. 2010;14(4):87-97.

29. Chibwesha CJ, Li MS, Matoba CK, Mbewe RK, Chi BH, Stringer JS, et al. Modern contraceptive and dual method use among HIV-infected women in Lusaka, Zambia. Infect Dis Obstet Gynecol. 2011;2011:Article ID 261453.

30. Seiber EE, Hotchkiss DR, Rous JJ, Berruti AA. Maternal and child health and family 491 planning service utilization in Guatemala: implications for service integration. Soc Sci Med. 2005;61(2):279-91.

\section{Publisher's Note}

Springer Nature remains neutral with regard to jurisdictional claims in published maps and institutional affiliations.

Ready to submit your research? Choose BMC and benefit from:

- fast, convenient online submission

- thorough peer review by experienced researchers in your field

- rapid publication on acceptance

- support for research data, including large and complex data types

- gold Open Access which fosters wider collaboration and increased citations

- maximum visibility for your research: over $100 \mathrm{M}$ website views per year

At $\mathrm{BMC}$, research is always in progress.

Learn more biomedcentral.com/submissions 